\title{
A Simple Mouse Model for the Study of Human Immunodeficiency Virus
}

\author{
Kang Chang Kim,, ${ }^{1,}$ Byeong-Sun Choi,, ${ }^{2}$ Kyung-Chang Kim, ${ }^{2}$ Ki Hoon Park, Hee Jung Lee, Young Keol Cho, \\ Sang II Kim, ${ }^{4}$ Sung Soon Kim, ${ }^{2}$ Yu-Kyoung Oh, and Young Bong Kim ${ }^{1}$
}

\begin{abstract}
Humanized mouse models derived from immune-deficient mice have been the primary tool for studies of human infectious viruses, such as human immunodeficiency virus (HIV). However, the current protocol for constructing humanized mice requires elaborate procedures and complicated techniques, limiting the supply of such mice for viral studies. Here, we report a convenient method for constructing a simple HIV-1 mouse model. Without prior irradiation, NOD/SCID/IL2R $\gamma$-null (NSG) mice were intraperitoneally injected with $1 \times 10^{7}$ adult human peripheral blood mononuclear cells (hu-PBMCs). Four weeks after PBMC inoculation, human CD45 ${ }^{+}$ cells, and $\mathrm{CD}^{+} \mathrm{CD}^{+}$and $\mathrm{CD} 3^{+} \mathrm{CD}^{+}{ }^{+}$cells were detected in peripheral blood, lymph nodes, spleen, and liver, whereas human $\mathrm{CD} 19^{+}$cells were observed in lymph nodes and spleen. To examine the usefulness of huPBMC-inoculated NSG (hu-PBMC-NSG) mice as an HIV-1 infection model, we intravenously injected these mice with dual-tropic HIV-1 $1_{D H 12}$ and X4-tropic HIV-1 ${ }_{N L 4-3}$ strains. HIV-1-infected hu-PBMC-NSG mice showed significantly lower human $\mathrm{CD}^{+} \mathrm{T}$ cell counts and high HIV viral loads in the peripheral blood compared with noninfected hu-PBMC-NSG mice. Following highly active antiretroviral therapy (HAART) and neutralizing antibody treatment, HIV-1 replication was significantly suppressed in HIV-1-infected hu-PBMCNSG mice without detectable viremia or $\mathrm{CD}^{+} \mathrm{T}$ cell depletion. Moreover, the numbers of human $\mathrm{T}$ cells were maintained in hu-PBMC-NSG mice for at least 10 weeks. Taken together, our results suggest that hu-PBMCNSG mice may serve as a relevant HIV-1 infection and pathogenesis model that could facilitate in vivo studies of HIV-1 infection and candidate HIV-1 protective drugs.
\end{abstract}

\section{Introduction}

O NE OF THE MAJOR PROBLEMS in the field of HIV-1 research is the lack of suitable, convenient, and inexpensive small-animal models for virological, pathological, and immunological studies. Current animal models of HIV-1 infection, such as the nonhuman primate model, have greatly enhanced our understanding of HIV-1 pathogenesis, and improved HIV-1 therapeutic design and efficacy. However, these animal models are associated with ethical problems and substantial maintenance costs.

To overcome these problems, researchers have developed humanized mouse models for studying HIV-1 infection. The first humanized mouse model was generated by engrafting the severe immunodeficiency (SCID) mouse with human fetal thymus or liver tissue. ${ }^{1,2}$ The hu-PBL-SCID mouse, another HIV mouse model created by transplanting human peripheral blood mononuclear cells (PBMCs), has been used as a tool in HIV-1 research for the development of antiretroviral therapies. ${ }^{3-5}$ However, this SCID mouse has a serious graft-versus-host rejection problem and requires a more immune-compromised strain. Although the upgraded nonobese diabetic (NOD/SCID) mouse has led to improved human cell engraftment, the percentage of engrafted human cells following intraperitoneal injection has remained suboptimal and highly variable..$^{6-10}$

NOD/SCID mice harboring either a null allele at the $\beta_{2^{-}}$ microglobulin locus (NOD/SCID/ $\left.\beta 2 \mathrm{~m}^{-/}\right)^{11}$ or a truncated common cytokine receptor $\gamma$ chain $(\gamma \mathrm{c})$ mutant lacking its cytoplasmic region (NOD/SCID $\left./ \gamma_{\mathrm{c}}{ }^{-/-}\right)^{12-14}$ were developed as

\footnotetext{
${ }^{1}$ Department of Bio-industrial Technologies, College of Animal Bioscience and Technology, Konkuk University, Seoul, Korea.

${ }^{2}$ Division of AIDS, Center for Immunology and Pathology, Korea National Institute of Health, Osong, Chungcheongbuk, Korea.

${ }^{3}$ Department of Microbiology, College of Medicine, University of Ulsan, Seoul, Korea.

${ }^{4}$ Division of Infectious Disease, Seoul St. Mary's Hospital, College of Medicine, the Catholic University of Korea, Seoul, Korea.

${ }^{5}$ Department of Manufacturing Pharmacy, College of Pharmacy and Research Institute of Pharmaceutical Sciences, Seoul National University, Seoul, Korea.

*These authors contributed equally to this work.
} 
model animals. In these mice, natural killer (NK) cells as well as $T$ and $B$ cells are disrupted because $\beta 2 \mathrm{~m}$ is necessary for major histocompatibility complex (MHC) class I-mediated innate immunity and $\gamma c$ (IL-2R $\gamma$ chain) is an indispensable component of receptor heterodimers for many lymphoidrelated cytokines, such as interleukin (IL)-2, IL-7, IL-9, IL-12, IL-15, and IL-21. ${ }^{15}$ Transplants of human bone marrow or cord blood cells into these mice result in successful differentiation of multilineage cells, including human $\mathrm{T}, \mathrm{B}$, and NK cells; monocytes/macrophages; and dendritic cells (DCs). ${ }^{12,13,16}$ The human $\mathrm{CD}^{+} \mathrm{T}$ cells in these mouse models can be infected with HIV-1. ${ }^{17-20}$ Moreover, these mice are highly susceptible to both CCR5 (R5)- and CXCR4 (X4)-tropic HIVs, exhibiting intense plasma viral loads lasting for over 40 days. ${ }^{16}$

Although these models have shown great promise in the HIV-1 research field, the requirement for human cord blood and hematopoietic stem cells coupled with the surgical skills needed for transplantation of human fetal tissues and irradiation of mice prevent these models from being widely available to all laboratories. Here, we used NOD/SCID/IL2R $\gamma^{\text {null }}$ (NSG) mice as recipients of human PBMCs and evaluated the resulting humanized mouse model of HIV-1 infection (hu-PBMCNSG mice) by tracking human $\mathrm{T}$ cell development in vivo and testing the responses of this model to HIV-1 infection and antiHIV-1 therapies.

\section{Materials and Methods}

\section{Mice}

NOD.Cg-PrkdcscidIL2rgtmlWjl/Sz [NOD/SCID/IL2R $\gamma^{\text {null }}$ (NSG)] mice were purchased from Jackson Laboratory (Bar Harbor, ME). NSG mice were maintained in accordance with the Guide for the Care and Use of Laboratory Animals of Konkuk University (Seoul, Republic of Korea), and were housed in an SPF facility. All experiments were performed according to the guidelines of the Institutional Animal Committee of Konkuk University (2012-008).

\section{Preparation and engraftment of PBMCs}

Human PBMCs were obtained from peripheral venous blood of healthy donors who tested negative for HIV-1 virus infections. Human PBMCs $\left(1 \times 10^{7}\right.$ cells $)$, purified by FicollPaque (Pharmacia, Piscataway, NJ) density gradient centrifugation, were resuspended in phosphate-buffered saline (PBS) and injected intraperitoneally into NSG mice.

\section{Immunohistochemistry}

For immunohistochemistry experiments, spleen, liver, and lymph node were removed 4 weeks after transplantation of NSG mice with human PBMCs. Organs were snap-frozen after embedding in OCT compound (Sakura Finetechnical, Tokyo, Japan). Cryostat sections ( $5 \mu \mathrm{m}$ thick) were air dried, fixed in acetone for $10 \mathrm{~min}$, immunostained with PC5conjugated antihuman CD3, fluorescein isothiocyanate (FITC)conjugated antihuman $\mathrm{CD} 4$, phycoerythrin (PE)-conjugated antihuman CD8, PE-conjugated antihuman CD19, and FITCconjugated antihuman CD45 (all from Beckman Coulter, Fullerton, CA), and further stained with the nuclear dye 4', 6-diamidino-2-phenylindole (DAPI; Invitrogen, Carlsberg, CA). Stained specimens were observed by confocal microscopy
(LSM510 META microscope; Carl Zeiss, Oberkochen, Germany). Image acquisition and data analysis were performed using LSM5 software. The numerical aperture of the objective lens (Plan Apochromat X63) was 1.4.

\section{HIV-1 infection and highly active antiretroviral therapy}

All procedures for HIV-1 infection and maintenance of hu-PBMC(ip)-NSG mice were performed in a biosafety level 3 animal facility at the Laboratory Animal Research Center of Konkuk University in accordance with protocols approved by the Institutional Animal Committee of Konkuk University. Four weeks after human PBMC engraftment, NSG mice were intraperitoneally injected with X4/R5 dual-tropic HIV-1 $1_{D H 12}\left(1 \times 10^{5} \mathrm{IU}\right)$. For highly active antiretroviral therapy (HAART) administration, HIV-1infected mice in one group were treated daily with a combination of $4.5 \mathrm{mg}$ of indinavir, $1.2 \mathrm{mg}$ of azidothymidine, and $0.4 \mathrm{mg}$ of atazanavir, administered orally, for 5 weeks. HIV-1-infected mice in a second group were treated daily with HAART for 2 weeks beginning 1 day after HIV-1 infection. Each experimental group consisted of five huPBMC(ip)-NSG mice. Mice were bled by tail nicking, and peripheral blood cell populations and plasma viral loads were analyzed periodically using flow cytometry and an HIV p24 $4_{\text {Gag }}$ antigen enzyme-linked immunosorbent assay (ELISA) kit (PerkinElmer, San Jose, CA).

\section{In vivo neutralization assay}

To evaluate the utility of the hu-PBMC-NSG mouse as an in vivo neutralization assay, we passively immunized mice with $068 \mathrm{P}$ polyclonal antibody, obtained from a naive HIV-1 ${ }_{\text {DH12 }}$-infected macaque monkey. ${ }^{21}$ The neutralizing titer of the 068P polyclonal antibody was over 128 . We initially infected hu-PBMC-NSG mice with $1 \times 10^{5}$ IU of HIV $-1_{D H 12}$ by intraperitoneal injection 4 weeks after reconstitution by intraperitoneal injection of PBMCs. Two days after HIV-1 infection, $50 \mu \mathrm{l}$ of PBS or 068P antibody was injected intraperitoneally into each of three hu-PBMC-NSG mice, and $\mathrm{CD} 4^{+} \mathrm{T}$ cell decay was monitored for 3 weeks. Each experimental group consisted of five hu-PBMC(ip)-NSG mice. Mice were bled by tail nicking, and peripheral blood cell populations and plasma viral loads were analyzed periodically using flow cytometry and an HIV p24 $4_{\mathrm{Gag}}$ antigen ELISA kit (PerkinElmer).

\section{In vivo assay of HIV-1 strain kinetics}

To determine the kinetics of $\mathrm{CD}^{+} \mathrm{T}$ cell deletion following infection with different HIV-1 strains, we infected hu-PBMC(ip)-NSG mice with a lower dose of dual tropic HIV-1 ${ }_{D H 12}$ or X4-tropic HIV-1 $1_{N L 4-3}$ strains 4 weeks after intraperitoneal injection of human PBMCs. Mice were infected by intraperitoneal injection of $1 \times 10^{3}$ IU of HIV $-1_{D H 12}$ or HIV $-1_{N L 4-3}$ in a $200-\mu 1$ volume. The HIV- $1_{N L 4-3}$ strain for this study was obtained from the HIV Resources Center of the National Institutes of Health (Bethesda, MD). Each experimental group consisted of five hu-PBMC(ip)-NSG mice. Mice were bled by tail nicking, and peripheral blood cell populations and plasma viral loads were analyzed periodically using flow cytometry and an HIV p24 $4_{\text {Gag }}$ antigen ELISA kit (PerkinElmer). 
Flow cytometry

Samples of peripheral blood were collected from the tail vein and stained for $30 \mathrm{~min}$ with PC5-conjugated antihuman CD3, FITC-conjugated antihuman CD4, PEconjugated antihuman CD8, and FITC-conjugated antihuman CD45. Stained peripheral blood samples were then lysed with red blood cell lysis buffer (BD Biosciences, San Jose, CA) and washed with PBS. Flow cytometry analyses were conducted by three-color staining using a FACSCalibur system and Cell Quest software (BD Biosciences).

\section{HIV antigen assay}

Plasma levels of HIV $-1_{D H 12}$ and HIV $-1_{N L 4-3}$ in HIV-1infected or uninfected (control) mice were determined by detecting HIV-specific antigens. The HIV p24 $4_{\text {Gag }}$ antigen ELISA kit (PerkinElmer) was used to quantify HIV $-1_{D H 12}$ and HIV $-1_{N L 4-3}$ in plasma samples, according to the manufacturer's instruction. All experiments were performed in triplicate.

\section{Statistics}

All measures of variance are presented as standard error of the mean (SEM). All data were analyzed by analysis of variance (ANOVA) with Student-Newman-Keuls as a post hoc test using SigmaStat software (Systat Software, Richmond, VA). Differences between independent means were assumed to be significant for $p$-values $<0.05$.

\section{Results}

\section{Sustainability of human T cells developed in NSG mice} following intraperitoneal injection of human PBMCs

HIV-1 infection causes an acquired immunodeficiency that is correlated with depletion of $\mathrm{CD}^{+} \mathrm{T}$ cells. Therefore, the presence of human $\mathrm{CD}^{+}$and $\mathrm{CD}^{+} \mathrm{T}$ cells in hu-PBMCNSG mice is important for the investigation of HIV-1 infection. Current methods for constructing humanized NSG mice involve intrahepatic or intravenous injection of fetal hematopoietic tissues or hematopoietic stem cells into previously irradiated newborn mice. ${ }^{22,23}$ To test whether intraperitoneal injection of human PBMCs affected the sustainability of human $\mathrm{T}$ cells in the plasma of hu-PBMCNSG mice, we analyzed human $\mathrm{CD}^{+}{ }^{+} \mathrm{CD} 4^{+}$and $\mathrm{CD} 3{ }^{+} \mathrm{CD} 8^{+}$ $\mathrm{T}$ cells in peripheral blood after injection of human PBMCs without prior irradiation.

To verify engraftment kinetics, we analyzed human leukocytes in the peripheral blood of hu-PBMC-NSG mice between 4 and 10 weeks after intraperitoneal injection of $1 \times 10^{7}$ human PBMCs, using 20 mice at each time point. We found that all mice exhibited high, stable engraftment of human $\mathrm{CD} 45^{+}$cells (Fig. 1A). Human $\mathrm{CD}^{+} \mathrm{T}$ cells were weakly detected during the first 2 to 3 weeks after intraperitoneal injection of human PBMCs; however, 4 weeks after intraperitoneal injection, the percentage of human $\mathrm{CD}^{+} \mathrm{T}$ cells rapidly increased, reaching peak levels of $79.1 \%$. Human $\mathrm{CD}^{+} \mathrm{T}$ cells were maintained for at least 10 weeks postinjection, at which point their levels were $62.3 \%$ (Fig. 1B). Moreover, hu-PBMC-NSG mice showed similar human
A

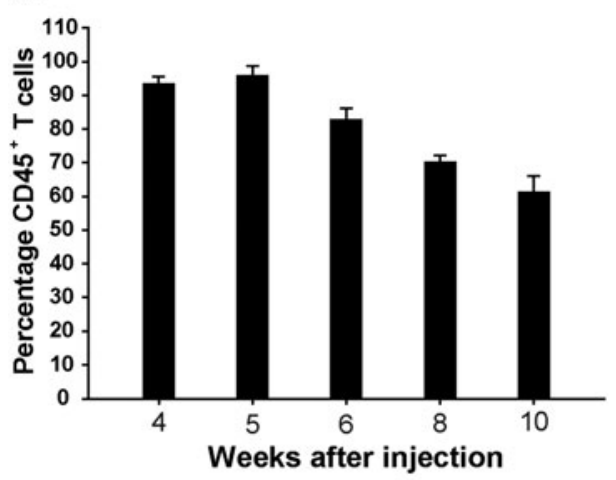

C

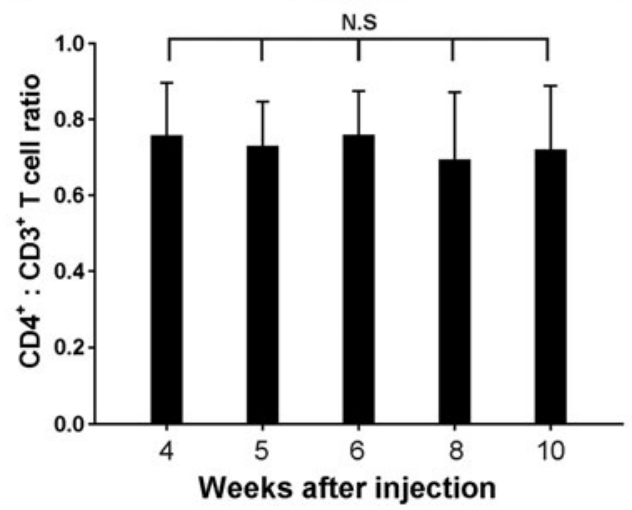

B

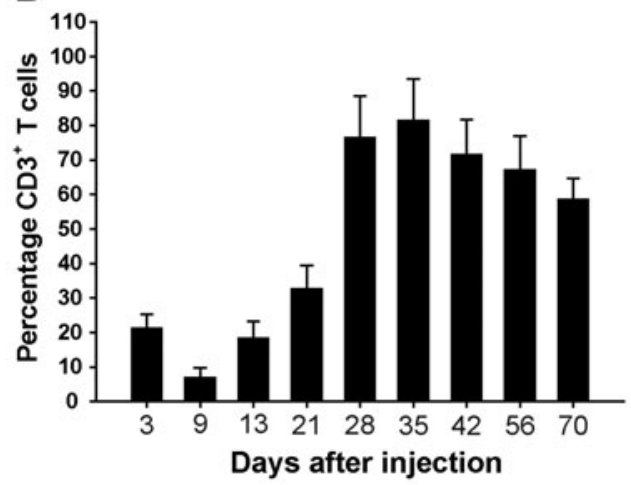

D

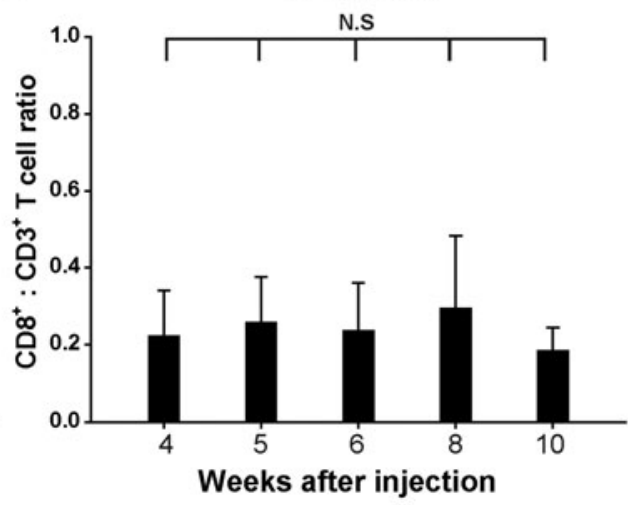

FIG. 1. Reconstitution of human immune cells in human peripheral blood mononuclear cells (hu-PBMC)-NSG mice. (A) The percentage of human CD45 ${ }^{+} \mathrm{T}$ cells in the peripheral blood of hu-PBMC-NSG mice $(n=20) \quad$ reconstituted with human PBMCs 4 to 10 weeks after intraperitoneal injection. (B) The percentage of human $\mathrm{CD}^{+} \mathrm{T}$ cells in the peripheral blood of huPBMC-NSG mice increased significantly 28 days after intraperitoneal injection $(p<$ 0.01 ). (C) $\mathrm{CD}^{+} / \mathrm{CD}^{+}$and (D) $\mathrm{CD}^{+} / \mathrm{CD}^{+} \mathrm{T}$ cell ratios in peripheral blood from NSG mice injected intraperitoneally with $1 \times 10^{7}$ human PBMCs $(n=20)$. Results are expressed as means \pm standard deviation (error bars); n.s., not significant $(p>0.05)$. Mice were bled at the indicated time points after injection of human PBMCs, and PBMCs were isolated for quantification of cell subsets by flow cytometry. 
$\mathrm{CD}^{+} / \mathrm{CD}^{+}$and $\mathrm{CD}^{+} / \mathrm{CD}^{+}{ }^{+} \mathrm{T}$ cell ratios between 4 and 10 weeks (Fig. 1C and D). We truncated the experiment at 10 weeks after injection. The reason is time-dependent development of graft-versus-host symptoms. Until 10 weeks after human PBMC injections, all hu-PBMC-NSG mice stably maintained human T cells. However, at 16 weeks after human PBMC injection, we observed graft-versus-host rejection for more than $80 \%$ of hu-PBMC NSG, such as all human T cell depletion and human $\mathrm{CD} 45^{+}$cells. However, the high human $\mathrm{CD}^{+} / \mathrm{CD}^{+} \mathrm{T}$ cell ratio in particular supports the model for studying $\mathrm{CD}^{+}$-targeting $\mathrm{HIV}$. These results suggest that hu-PBMC-NSG mice are a simple model for inducing the effective repopulation of human $\mathrm{T}$ cells, and indicate that homeostatic regulation mechanisms may remain intact in this humanized model system.

\section{Distribution of human cells in the organs of hu-PBMC-NSG mice}

Secondary lymphoid tissues are the sites where the majority of lymphocytes reside in humans. They are also the sites of antigen presentation and lymphocyte activation, and are therefore critical venues for HIV-1 replication and the establishment of HIV-1 latency. ${ }^{24,25}$ Therefore, we analyzed the distributions of human $\mathrm{CD} 19^{+}$and $\mathrm{CD} 45^{+}$cells, and $\mathrm{CD}^{+} \mathrm{CD}^{+}$and $\mathrm{CD}^{+} \mathrm{CD}^{+} \mathrm{T}$ cells in secondary lymphoid tissues, including lymph node, spleen, and liver, in huPBMC-NSG mice (Fig. 2). These immunohistochemistry analyses revealed that approximately 4 weeks after intra- peritoneal injection, human $\mathrm{CD} 45^{+}$cells were prominent in all organs examined, but human $\mathrm{CD} 19^{+}$cells were detected only in lymph node and spleen. Human $\mathrm{CD}^{+} \mathrm{T}$ cells were observed in lymph node, spleen, and liver, but distribution patterns of $\mathrm{CD}^{+}$and $\mathrm{CD}^{+}$subpopulations were different. In the spleen, the majority of human $\mathrm{CD}^{+} \mathrm{T}$ cells in the red pulp were $\mathrm{CD}^{+} \mathrm{T}$ cells, whereas most human $\mathrm{CD} 4^{+} \mathrm{T}$ cells were found in the white pulp (Fig. 2A). Human $\mathrm{CD}^{+} \mathrm{T}$ cells were also found surrounding the periportal areas of the liver, whereas human $\mathrm{CD} 4^{+} \mathrm{T}$ cells were more diffusely distributed throughout the tissues (Fig. 2B). Lymph nodes were densely populated by human $\mathrm{CD}^{+}$and $\mathrm{CD}^{+} \mathrm{T}$ cells (Fig. 2C), whereas mouse $\mathrm{T}$ cells were very rare. The CD4/CD8 ratio of PBMC donor was $1.94 \pm 0.23$, which is in a normal CD4/CD8 ratio range. However, the $\mathrm{CD} 4 / \mathrm{CD} 8$ ratio of peripheral blood in hu-PBMC-NSG mice increased 2-fold higher than those of the PBMC donor. Once increased, the CD4/CD8 ratios of huPBMC-NSG mice did not significantly change between 4 and 10 weeks. Moreover, although human B cells were barely detected in peripheral blood of hu-PBMC-NSG mice, human IgG was detected in hu-PBMC NSG mice at 4 weeks postinjection

Collectively, immunohistological analyses showed that the lymphoid tissues of recipient mice contained significant numbers of human $\mathrm{CD}^{+} \mathrm{CD}^{+}$and $\mathrm{CD}^{+} \mathrm{CD}^{+} \mathrm{T}$ cells, which are critical for the establishment and maintenance of persistent HIV-1 infection in humans. Thus, the distribution of human $\mathrm{T}$ cells in these lymphoid and peripheral tissues suggests that intraperitoneally injected hu-PBMC-NSG mice
FIG. 2. Immunohistochemical analysis of human cells in hu-PBMC-NSG mouse tissues. Representative immunohistochemical analyses of human CD $45^{+}$cells (green), $\mathrm{CD}^{4} 5^{+} \mathrm{T}$ cells (orange), $\mathrm{CD}^{+} \mathrm{T}$ cells (red), $\mathrm{CD}^{+} \mathrm{T}$ cells (green), and $\mathrm{CD}^{+} \mathrm{T}$ cells (orange) in slices from spleen (A), liver (B), and lymph node (C) of hu-PBMCNSG mice 4 weeks after intraperitoneal injection. Sections were counterstained with the nuclear dye DAPI (blue). Color images available online at www.liebertpub.com/aid

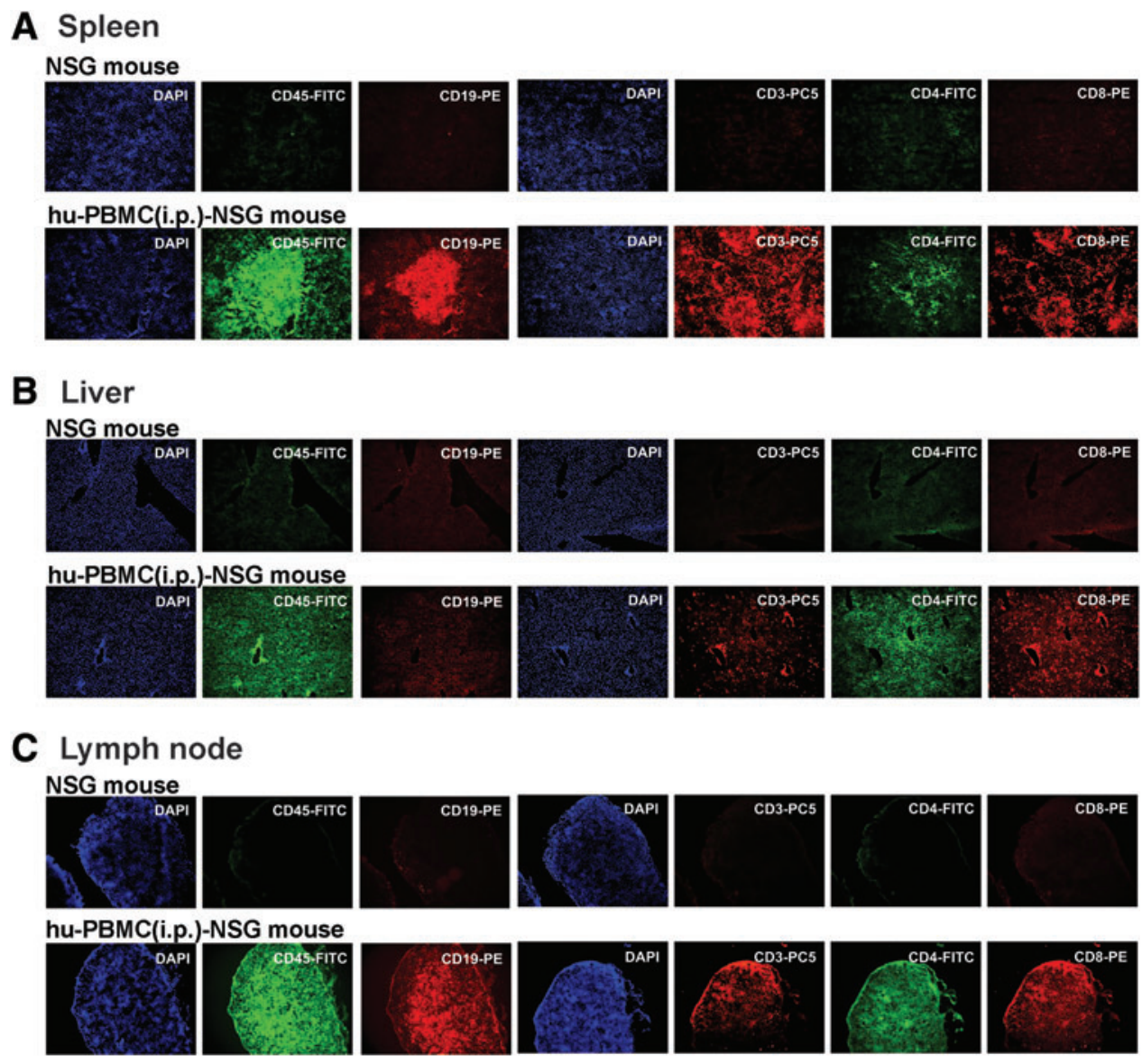
NSG mouse

hu-PBMC(i.p.)-NSG mouse

NSG mouse

\section{NSG mouse}


may facilitate in vivo studies of HIV-1 and other human T cell tropic viral infections.

\section{Hu-PBMC-NSG mice as an HIV-1 infection model and in vivo HIV-1 antiviral assay}

To evaluate HIV-1 infection in hu-PBMC-NSG mice, we inoculated these mice with dual tropic HIV- $1_{D H 12}\left(1 \times 10^{5}\right.$ $\mathrm{IU})$ and monitored human $\mathrm{CD} 4^{+} \mathrm{T}$ cell count and plasma viral load for 5 weeks. Figure $3 \mathrm{~A}$ shows the human $\mathrm{CD} 4^{+} / \mathrm{CD}^{+} \mathrm{T}$ cell ratios and p24 Ag levels in peripheral blood. In a representative HIV- $1_{D H 12}$-infected hu-PBMC-NSG mouse, the $\mathrm{CD}^{+} / \mathrm{CD}^{+} \mathrm{T}$ cell ratio in peripheral blood decreased sig-
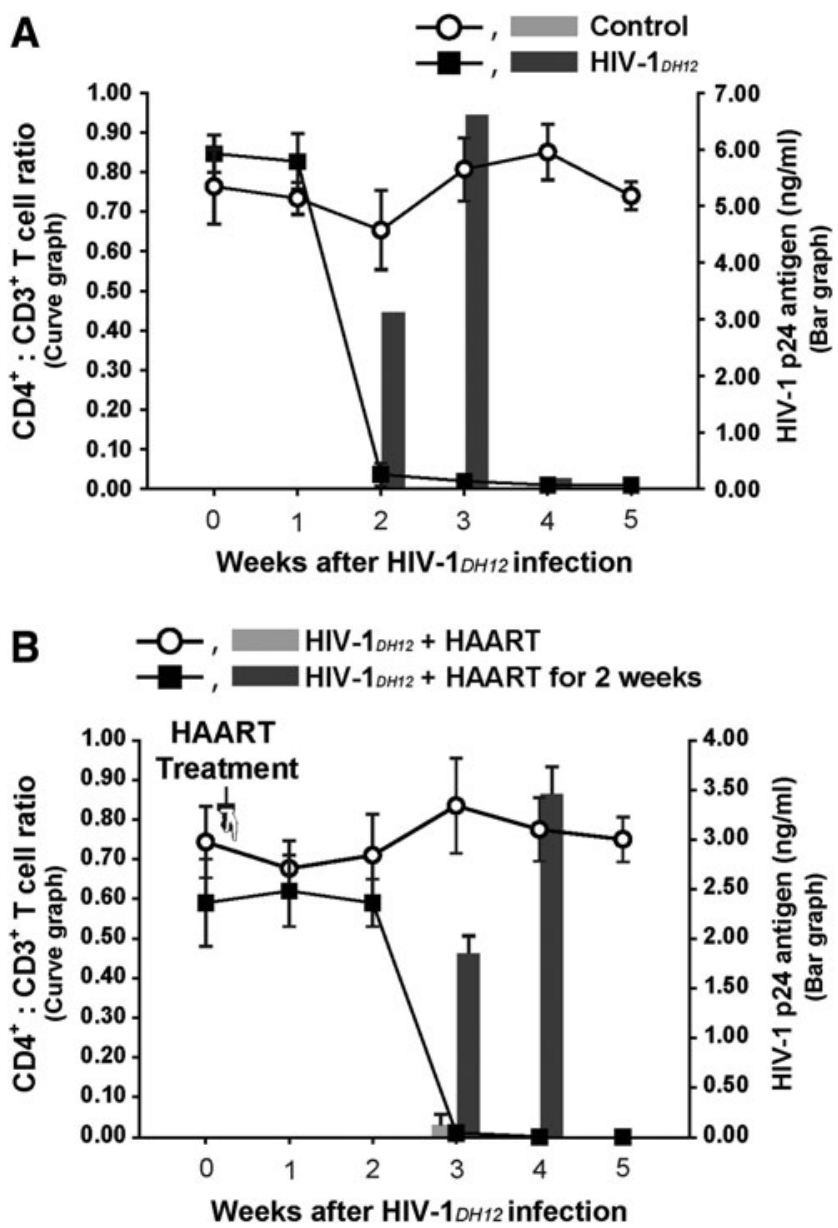

FIG. 3. HIV $-1_{D H 12}$ infection and antiviral therapy in huPBMC-NSG mice. (A) Human $\mathrm{CD}^{+}{ }^{+} \mathrm{T}$ cell depletion and HIV-1 p24 Ag detection in HIV-1 ${ }_{D H 12}$-infected huPBMC-NSG mice (HIV-1 $\left.1_{D H 12}, n=5\right)$ and uninfected huPBMC-NSG mice (control, $n=5$ ). (B) Quantification of human $\mathrm{CD}^{+} \mathrm{T}$ cell reconstitution and HIV-1 p24 levels in blood of HIV-1 $1_{D H 12}$-infected mice administered HAART for 5 weeks (HIV-1 $1_{D H 12}+$ HAART) and only 2 weeks (HIV $-1_{D H 12}+$ HAART for 2 weeks). Mice were infected with HIV-1 ${ }_{D H 12}\left(1 \times 10^{5} \mathrm{IU}\right)$ for 2 days and then administered a HAART regimen consisting of $4.5 \mathrm{mg}$ of indinavir, $1.2 \mathrm{mg}$ of azidothymidine, and $0.4 \mathrm{mg}$ of atazanavir per mouse. Lines show human $\mathrm{CD}^{+} / \mathrm{CD}^{+} \mathrm{T}$ cell ratios; squares show HIV-1 p24 levels analyzed by ELISA. Results are expressed as means \pm standard deviation (error bars). nificantly 2 weeks postinfection, reflecting an almost complete depletion of human $\mathrm{CD}^{+}$T cells (Fig. 3A). However, uninfected hu-PBMC-NSG mice consistently maintained high human $\mathrm{CD}^{+} / \mathrm{CD}^{+} \mathrm{T}$ cell ratios in peripheral blood. To evaluate the plasma viral load in HIV-1 $1_{D H 12}$-infected mice, we measured HIV-1 p24 antigen by ELISA (Fig. 3A). In these mice, HIV-1 p24 antigen levels rapidly increased to 3.1 and $6.6 \mathrm{ng} / \mathrm{ml}$ at 2 and 3 weeks, respectively. At the time corresponding to a high plasma viral load, the human $\mathrm{CD}^{+}$/ $\mathrm{CD}^{+} \mathrm{T}$ cell ratio was dramatically decreased in the peripheral blood of HIV-1-infected mice. Because host $\mathrm{CD}^{+}$ $\mathrm{T}$ cells were depleted, the production of HIV- $1_{D H 12}$ also decreased, dropping to $0.2 \mathrm{ng} / \mathrm{ml}$ at 4 weeks and to below the limit of detection at 5 weeks. Thus, these results show that huPBMC-NSG mice intraperitoneally injected with human PBMCs are readily infected with HIV-1 $1_{D H 12}$, resulting in a high plasma viral load and depletion of human $\mathrm{CD}^{+} \mathrm{T}$ cells in the peripheral blood.

To evaluate hu-PBMC-NSG mice as an in vivo antiviral assay model, we administered a HAART protocol consisting of the HIV nucleoside/nucleotide reverse transcriptase inhibitor azidothymidine and the protease inhibitors indinavir and ata-

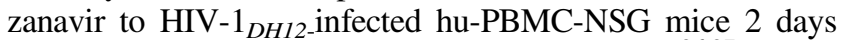
postinfection (Fig. 3B). Similar to previous reports, ${ }^{26,27}$ plasma viral loads were suppressed to below the limit of detection with HAART at 5 weeks. In addition to evaluating the effect of HAART on systemic virus production in hu-PBMC-NSG mice, we assessed the effect of discontinuing antiviral drugs 2 weeks after initiating treatment (Fig. 3B). HAART interruption resulted in a rapid rebound of HIV-1 p24 antigen, which reached a level of $1.8 \mathrm{ng} / \mathrm{ml}$ at 1 week and $3.5 \mathrm{ng} / \mathrm{ml}$ at 2 weeks after interrupting treatment. At the time corresponding to a high plasma viral load, the human $\mathrm{CD}^{+} / \mathrm{CD}^{+} \mathrm{T}$ cell ratio in peripheral blood was significantly decreased (to nearly zero). Collectively, these results illustrate the utility of our hu-PBMCNSG mouse model for evaluating HIV-1 antiviral drugs in vivo.

\section{Hu-PBMC-NSG mice as an in vivo HIV-1 neutralizing antibody assay}

Vaccine studies in chimpanzee models show a good correlation between protection and serum neutralizing antibodies following challenge with HIV-1 or SHIV. ${ }^{21,28-36} \mathrm{We}$ therefore tested whether a neutralizing antibody effectively blocked infection when administered after HIV-1 challenge, as this would have a profound impact on the potential clinical usefulness of the hu-PBMC-NSG mouse model. The neutralizing antibody 068P, obtained from serum from an HIV$1_{D H 12}$-infected and recovered macaque monkey, was used for passive immunization after HIV-1 infection. Unlike the PBStreated group, hu-PBMC-NSG mice treated with neutralizing antibody showed no decay in the $\mathrm{CD} 4^{+} \mathrm{T}$ cell subpopulation (Fig. 4). This result indicates that HIV-1 infection was inhibited by the neutralizing antibody, highlighting the usefulness of the hu-PBMC-NSG mouse model for evaluating the effectiveness of HIV-1 neutralizing antibodies in vivo.

\section{Hu-PBMC-NSG mice as an in vivo HIV-1 kinetic assay}

To determine the kinetics of HIV-1 replication in vivo, we infected hu-PBMC-NSG mice with $1 \times 10^{3} \mathrm{IU}$ of dual tropic HIV- $1_{D H 12}$ or X4-tropic HIV-1 $1_{N L 4-3}$, and monitored human $\mathrm{CD} 4^{+} \mathrm{T}$ cells. After infection with the HIV $-1_{D H 12}$ strain, 


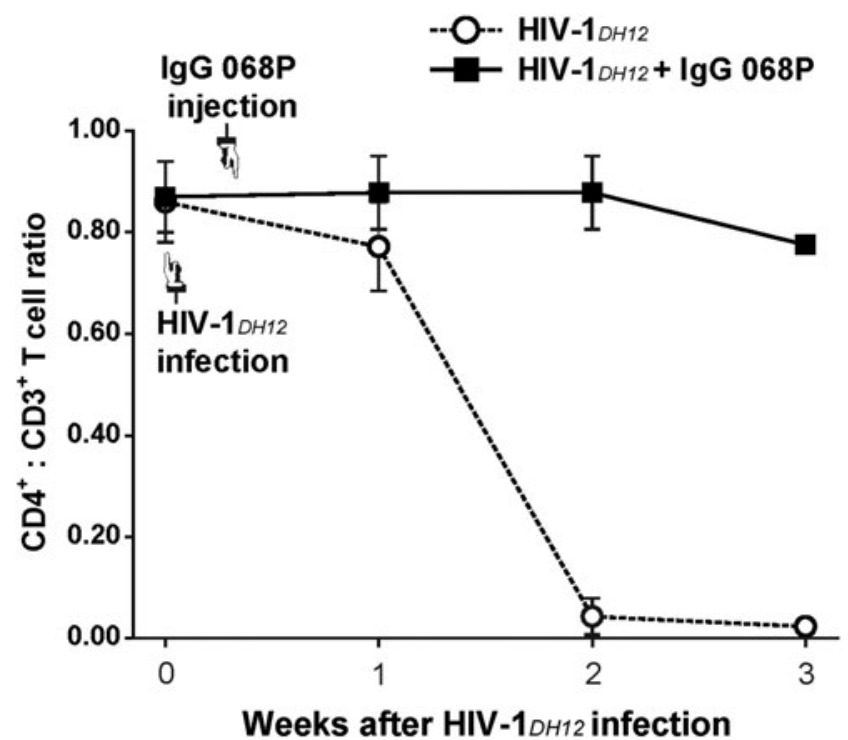

FIG. 4. Hu-PBMC-NSG mice as an in vivo HIV-1 neutralizing-antibody assay. Hu-PBMC-NSG mice $(n=5)$ were infected with $1 \times 10^{5} \mathrm{IU}$ of HIV-1 ${ }_{D H 12} 4$ weeks after injection of human PBMCs. After 2 days, mice were injected with $50 \mu \mathrm{l}$ of 068P antibody obtained from an HIV-1-infected and recovered macaque monkey ( $\square$ ) or $50 \mu$ l of phosphate-buffered saline (PBS) ( $\bigcirc$ ). Mice were bled at the indicated time points after infection with HIV-1 $1_{D H 12}$, and PBMCs were isolated for quantification of cell subsets by flow cytometry. Results are expressed as means \pm standard deviation (error bars).

$\mathrm{CD}^{+} \mathrm{T}$ cells in the peripheral blood of hu-PBMC-NSG mice were significantly depleted at 3 weeks postinfection, and no residual $\mathrm{CD}^{+} \mathrm{T}$ cells were detected 5 weeks after infection. By contrast, depletion of $\mathrm{CD}^{+}{ }^{+} \mathrm{T}$ cells in the peripheral blood was delayed in hu-PBMC-NSG mice infected with the HIV$1_{N L 4-3}$ strain 4 weeks after infection (Fig. 5). These results demonstrate a strain-dependent difference in the kinetics of $\mathrm{CD}^{+} \mathrm{T}$ cell depletion. To evaluate the plasma viral load in HIV-1 ${ }_{D H 12^{-}}$and HIV- $1_{N L 4-3}$-infected mice, we measured the HIV-1 p24 antigen by ELISA. In HIV-1 ${ }_{D H 12}$-infected mice, the production of the HIV-1 p24 antigen rapidly increased at 3 weeks postinfection, reaching a level of $3.6 \mathrm{ng} / \mathrm{ml}$, but decreased to $0.3 \mathrm{ng} / \mathrm{ml} 4$ weeks after infection (Fig. 5). Plasma viral load and $\mathrm{CD} 4^{+} \mathrm{T}$ cell levels were well correlated: as the viral load rapidly increased in the peripheral blood of HIV$1_{D H 12}$-infected mice, the human $\mathrm{CD}^{+} \mathrm{T}$ cell subpopulation dramatically decreased. However, the changes in p24 expression and decreases in $\mathrm{CD}^{+} \mathrm{T}$ cell counts induced by HIV $-1_{N L 4-3}$ infection were slower than those induced by HIV$1_{\text {DH12 }}$ infection (Fig. 5). The production of p24 reached a peak level of $2.0 \mathrm{ng} / \mathrm{ml}$ at 4 weeks after infection with HIV$1_{N L 4-3}$; this compares with a peak of $3.6 \mathrm{ng} / \mathrm{ml} 3$ weeks after infection with HIV $-1_{D H 12}$. Thus, the different $\mathrm{CD} 4^{+} \mathrm{T}$ cell depletion rates in hu-PBMC-NSG mice following infection with different HIV-1 strains demonstrates that this mouse model is suitable for in vivo viral kinetic studies.

\section{Discussion}

In this study, we took advantage of the NOD/SCID/IL $2 \mathrm{R} \gamma$ null (NSG) strain to generate a hu-PBMC-NSG mouse by
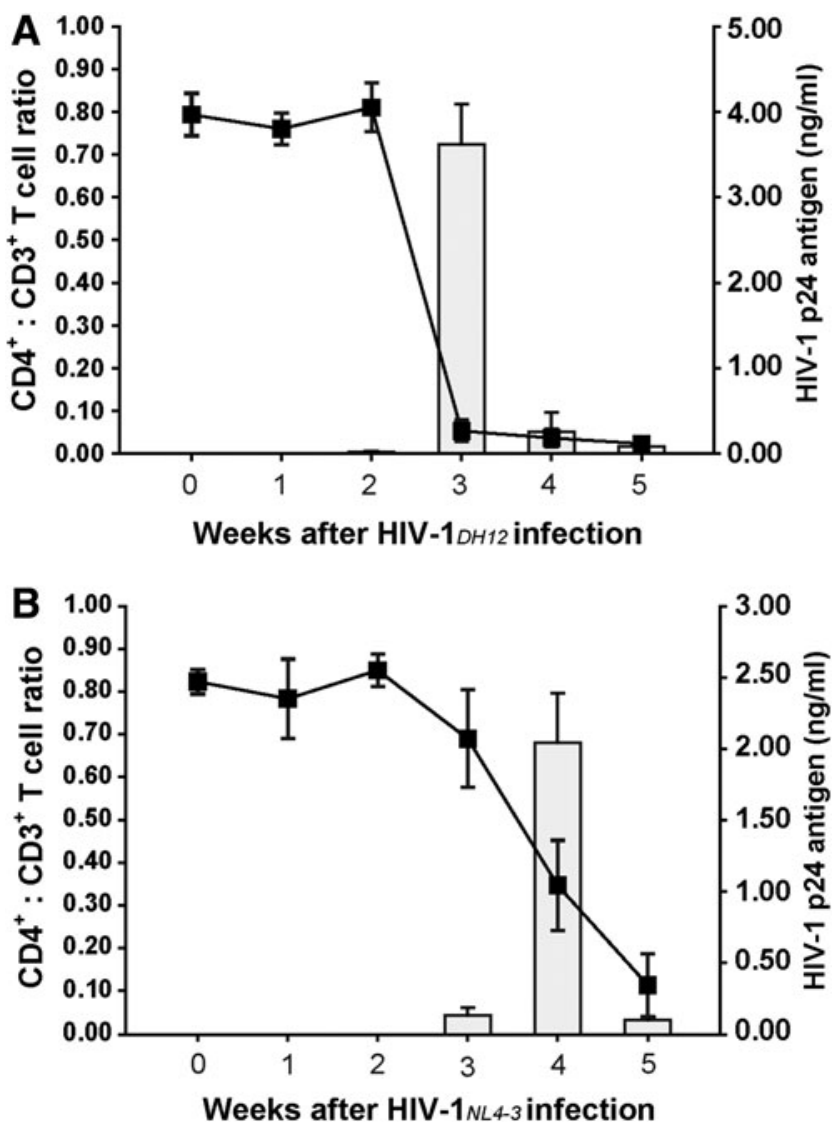

FIG. 5. Comparison of viral kinetics in hu-PBMC-NSG mice infected with two different tropic HIV-1 strains, HIV$1_{D H 12}$ and HIV-1 $1_{N L 4-3}$. (A) Human $\mathrm{CD}^{+}{ }^{+} \mathrm{T}$ cell depletion (line) and HIV-1 p24 Ag detection (square) in hu-PBMCNSG mice $(n=5)$ infected with $1 \times 10^{3}$ IU of HIV $-1_{D H 12} 4$ weeks after intraperitoneal injection of human PBMCs. (B) Human $\mathrm{CD}^{+} \mathrm{T}$ cell depletion (line) and HIV-1 p24 Ag detection (square) in hu-PBMC-NSG mice $(n=5)$ infected with $1 \times 10^{3}$ IU of $\mathrm{HIV}-1_{N L 4-3} 4$ weeks after intraperitoneal injection of human PBMCs. Mice were bled at the indicated time points after infection with HIV $-1_{D H 12}$ or HIV $-1_{N L A-3}$; PBMCs were isolated for quantification of cell subsets by flow cytometry, and HIV-1 p24 levels in blood were analyzed by ELISA. Results are expressed as means \pm standard deviation (error bars).

intraperitoneal injection of human PBMCs without prior gamma irradiation, highlighting the utility of this method in HIV-1 research. The generation of immunodeficient NSG mice has proved highly valuable for research of human cells and tissue, ${ }^{37-39}$ but a number of issues limit their widespread laboratory application, including the bewildering number of available strains and engraftment protocols. Therefore, we investigated the potential of NSG mice to support engraftment by human PBMCs. We found that the hu-PBMC-NSG mice could be an in vivo model for HIV-1 infection, antiviral assays, and neutralizing assays, demonstrating its viability as an HIV-1 research tool.

We observed that consistently high levels of human $\mathrm{CD}^{+}$ $T$ cells could be achieved in NSG mice after intraperitoneal injection of PBMCs (Fig. 1). Moreover, our analysis of $\mathrm{CD}^{+}$ $\mathrm{T}$ cell subpopulations revealed significant stabilization of 
human $\mathrm{CD}^{+} / \mathrm{CD}^{+}$and $\mathrm{CD}^{+} / \mathrm{CD}^{+}{ }^{+} \mathrm{T}$ cell ratios in huPBMC-NSG mice in peripheral blood for at least 6 weeks after intraperitoneal injection. These results suggest that huPBMC-NSG mice are an appropriate animal model for studying short-term HIV infection. Although numerous studies have employed the hu-PBMC-SCID model, the reconstitution of SCID mice with human engrafted cells is not consensual; thus, these mice are xenoreactive, often resulting in lethal graft-versus-host rejection. However, a recent study demonstrated that human $\mathrm{T}$ cells could be efficiently engrafted by direct transplantation of human PBMCs into the spleen of irradiated NOD/SCID $/ \gamma_{c}{ }^{-/-}$mice, creating an animal model for studying primary human $\mathrm{T}$ cell leukemia virus type-1 (HTLV-1) infection in vivo. ${ }^{14}$

Interestingly, reconstitution of human $\mathrm{T}$ cells was barely detectable in any of the NSG mice early (2 weeks) after intraperitoneal injection of human PBMCs (Fig. 1B). This presumably reflects delayed entry of human PBMCs into the bloodstream and retention in the peritoneal cavity, although the process responsible for this effect remains unknown. Human $\mathrm{CD}^{+}{ }^{+}$cells were reconstituted 3 weeks after injection of $1 \times 10^{7}$ PBMCs, a significantly lower cell dose than that needed to achieve engraftment of human PBMCs in earlier immunodeficient mouse models $\left(5-30 \times 10^{7}\right),{ }^{7-9,40,41}$ and reached a high level of engraftment after 4 weeks. Furthermore, the lymphoid tissues of hu-PBMC-NSG mice contained significant numbers of human $\mathrm{CD}^{+} 5^{+}$cells, whereas human $\mathrm{CD} 19^{+}$cells were found in lymph nodes and spleen. Human cells containing CD45 and T cells rapidly increased at 4 weeks after intraperitoneal injection. We thus observed CD45 cells in lymphoid organs at 4 weeks after injection of human PBMC.

Notably, human $\mathrm{CD}^{+} \mathrm{CD}^{+}$and $\mathrm{CD} 3^{+} \mathrm{CD} 8^{+} \mathrm{T}$ cells, which are critical for the establishment and maintenance of persistent HIV-1 infection in humans, constituted the major cell populations in several lymphoid tissues, including the lymph node, spleen, and liver (Fig. 2). These results are consistent with previous studies showing the presence of these cell types in several lymphoid tissues of hu-PBL-SCID, SCID-hu (Thy/ Liv), and hu-Rag $2^{-1-} \mathrm{rc}^{-/-}$mouse models. ${ }^{40,42-45}$ Therefore, hu-PBMC-NSG mice carrying human T cells in peripheral blood may be much easier and simpler model for studies of HIV-1 infection and anti-HIV-1 therapies than the previous mouse models.

To establish the utility of our novel humanized mouse model system for the analysis of HIV-1 infection, we intravenously injected hu-PBMC-NSG mice with the dual tropic HIV-1 $1_{D H 12}$. HIV-1 $1_{D H 12}$-infected hu-PBMC-NSG mice exhibited reduced human $\mathrm{CD} 4^{+} / \mathrm{CD}^{+} \mathrm{T}$ cell ratios in peripheral blood compared with uninfected control mice (Fig. 3A); viral load also increased in these mice. These results are consistent with previous studies showing that hu-PBL-SCID mice are readily infected with $\mathrm{HIV}_{D H 12}$ and show a rapid loss of human $\mathrm{CD}^{+}{ }^{+}$cells. $^{3}$ Moreover, plasma viral loads were suppressed to below the limit of detection with HAART (Fig. 3B) and by treatment with the neutralizing antibody $068 \mathrm{P}$, obtained from the serum from an HIV-1 ${ }_{D H 12}$-infected and recovered macaque monkey (Fig. 4).

We observed a rapid rebound of plasma viremia and a rapid depletion of $\mathrm{CD} 4 \mathrm{~T}$ cells by HAART treatment interruption compared to HIV-1-infected hu-PBMC-NSG mice (Fig. 3). We need to conduct further studies to clarify this observation. Currently, we speculate that the latent HIV-1 virus with HAART treatment may have presumably induced boosting effects of pathogenicity by interruption.

A comparison of viral kinetics in hu-PBMC-NSG mice infected with two different tropic HIV-1 strains (Fig. 5) showed that infection with dual-tropic HIV-1 $1_{D H 12}$ led to a more rapid loss of $\mathrm{CD}^{+} \mathrm{T}$ cells compared with that observed for infection with X4-tropic $\mathrm{HIV}-1_{N L A-3}$, where $\mathrm{CD}^{+} \mathrm{T}$ cell depletion and HIV-1 p24 production were delayed. In our study, the numbers of human CD8 T cells were maintained when human CD4 T cells were depleted in peripheral blood of HIV-1-infected hu-PBMC-NSG mice (data not shown).

A previous study has shown that CXCR4 and CCR5 are expressed mainly on naive $\mathrm{CD}^{+}{ }^{+} \mathrm{T}$ cells and memory $\mathrm{T}$ cells, respectively. ${ }^{46}$ In addition, it has been reported that most human $\mathrm{CD}^{+}{ }^{+} \mathrm{T}$ cells recovered from the peripheral cavity in the human peripheral blood leukocyte-SCID mouse model have the characteristics of memory or activated T cells. ${ }^{47,48}$ The coreceptor and phenotype of these cells likely accounted for faster progression of viral infection with the dual tropic $\mathrm{HIV}-1_{D H 12}$ compared with the X4tropic HIV- $1_{N L 4-3}$.

The susceptibility of hu-PBMC-NSG mice to HIV-1 demonstrates the overall utility of this animal model for studying HIV-1 infection and evaluating the effectiveness of new antiviral drugs and neutralizing antibodies against HIV-1. Moreover, the strain-dependent differences in kinetics of HIV-1 replication in hu-PBMC-NSG mice make this animal model suitable for viral kinetic studies in vivo.

\section{Conclusions}

Although our hu-PBMC-NSG mice exhibited short-term development of human $T$ cells, their engraftment efficiency was higher than that of previous models of human PBMC engraftment in immunodeficient mice. Thus, this novel humanized mouse model, which unlike previous models of human PBMC engraftment in immunodeficient mice requires neither advanced surgical skills nor irradiation of the host mice, shows great promise as a simple experimental tool for in vivo studies of initial HIV-1 infection and pathogenesis, as well as evaluation of new HIV-1 therapeutic drugs.

\section{Acknowledgments}

This research was supported by extramural grants from the Korea National Institute of Health (grants 2010E0075800, 2011E5100600, and 2013E5101000).

\section{Author Disclosure Statement}

No competing financial interests exist.

\section{References}

1. Namikawa R, Kaneshima H, Lieberman M, et al.: Infection of the SCID-hu mouse by HIV-1. Science 1988;242(4886): 1684-1686.

2. McCune JM, Namikawa $\mathrm{R}$, Kaneshima $\mathrm{H}$, et al.: The SCID-hu mouse: Murine model for the analysis of human hematolymphoid differentiation and function. Science 1988; 241(4873):1632-1639. 
3. Mosier DE: Adoptive transfer of human lymphoid cells to severely immunodeficient mice: Models for normal human immune function, autoimmunity, lymphomagenesis, and AIDS. Adv Immunol 1991;50:303-325.

4. Torbett BE, Picchio G, and Mosier DE: hu-PBL-SCID mice: A model for human immune function, AIDS, and lymphomagenesis. Immunol Rev 1991;124:139-164.

5. Ruxrungtham $\mathrm{K}$, Boone E, Ford $\mathrm{H} \mathrm{Jr}$, et al.: Potent activity of 2'-beta-fluoro-2',3'-dideoxyadenosine against human immunodeficiency virus type 1 infection in hu-PBL-SCID mice. Antimicrob Agents Chemother 1996;40(10):23692374.

6. Hesselton RM, Koup RA, Cromwell MA, et al.: Human peripheral blood xenografts in the SCID mouse: Characterization of immunologic reconstitution. J Infect Dis 1993;168(3):630-640.

7. Murphy WJ, Bennett M, Anver MR, et al.: Human-mouse lymphoid chimeras: Host-vs.-graft and graft-vs.-host reactions. Eur J Immunol 1992;22(6):1421-1427.

8. Hoffmann-Fezer G, Gall C, Zengerle U, et al.: Immunohistology and immunocytology of human T-cell chimerism and graft-versus-host disease in SCID mice. Blood 1993;81(12):3440-3448.

9. Martino G, Anastasi J, Feng J, et al.: The fate of human peripheral blood lymphocytes after transplantation into SCID mice. Eur J Immunol 1993;23(5):1023-1028.

10. Greiner DL, Hesselton RA, and Shultz LD: SCID mouse models of human stem cell engraftment. Stem Cells 1998; 16(3):166-177.

11. Kollet O, Peled A, Byk T, et al.: Beta2 microglobulindeficient (B2m(null)) NOD/SCID mice are excellent recipients for studying human stem cell function. Blood 2000;95(10):3102-3105.

12. Ito M, Hiramatsu $\mathrm{H}$, Kobayashi $\mathrm{K}$, et al.: NOD/SCID/ gamma(c)(null) mouse: An excellent recipient mouse model for engraftment of human cells. Blood 2002;100(9): 3175-3182.

13. Hiramatsu H, Nishikomori R, Heike $\mathrm{T}$, et al.: Complete reconstitution of human lymphocytes from cord blood CD34+ cells using the NOD/SCID/gammacnull mice model. Blood 2003;102(3):873-880.

14. Saito M, Tanaka R, Fujii H, et al.: The neutralizing function of the anti-HTLV-1 antibody is essential in preventing in vivo transmission of HTLV-1 to human T cells in NODSCID/inverted question markcnull (NOG) mice. Retrovirology 2014;11(1):74.

15. Leonard WJ: Cytokines and immunodeficiency diseases. Nat Rev Immunol 2001;1(3):200-208.

16. Watanabe $\mathrm{S}$, Terashima $\mathrm{K}$, Ohta $\mathrm{S}$, et al.: Hematopoietic stem cell-engrafted NOD/SCID/IL2Rgamma null mice develop human lymphoid systems and induce long-lasting HIV-1 infection with specific humoral immune responses. Blood 2007;109(1):212-218.

17. Denton PW, Krisko JF, Powell DA, et al.: Systemic administration of antiretrovirals prior to exposure prevents rectal and intravenous HIV-1 transmission in humanized BLT mice. PLoS One 2010;5(1):e8829.

18. Denton PW, Olesen R, Choudhary SK, et al.: Generation of HIV latency in humanized BLT mice. J Virol 2012;86(1): 630-634.

19. Shimizu S, Hong P, Arumugam B, et al.: A highly efficient short hairpin RNA potently down-regulates CCR5 expression in systemic lymphoid organs in the hu-BLT mouse model. Blood 2010;115(8):1534-1544.
20. Stoddart CA, Maidji E, Galkina SA, et al.: Superior human leukocyte reconstitution and susceptibility to vaginal HIV transmission in humanized NOD-scid IL-2Rgamma(-/-) (NSG) BLT mice. Virology 2011;417(1):154-160.

21. Cho MW, Kim YB, Lee MK, et al.: Polyvalent envelope glycoprotein vaccine elicits a broader neutralizing antibody response but is unable to provide sterilizing protection against heterologous simian/human immunodeficiency virus infection in pigtailed macaques. J Virol 2001;75(5): 2224-2234.

22. van Rijn RS, Simonetti ER, Hagenbeek A, et al.: A new xenograft model for graft-versus-host disease by intravenous transfer of human peripheral blood mononuclear cells in RAG2-/- gammac-/- double-mutant mice. Blood 2003; 102(7):2522-2531.

23. Mutis T, van Rijn RS, Simonetti ER, et al.: Human regulatory $\mathrm{T}$ cells control xenogeneic graft-versus-host disease induced by autologous $\mathrm{T}$ cells in RAG2-/-gammac-/- immunodeficient mice. Clin Cancer Res 2006;12(18):55205525.

24. Pantaleo G, Graziosi C, Demarest JF, et al.: HIV infection is active and progressive in lymphoid tissue during the clinically latent stage of disease. Nature 1993;362(6418): 355-358.

25. Marsden MD, Kovochich M, Suree N, et al.: HIV latency in the humanized BLT mouse. J Virol 2012;86(1):339-347.

26. Choudhary SK, Rezk NL, Ince WL, et al.: Suppression of human immunodeficiency virus type 1 (HIV-1) viremia with reverse transcriptase and integrase inhibitors, CD4+ Tcell recovery, and viral rebound upon interruption of therapy in a new model for HIV treatment in the humanized Rag2-/\{gamma\}c-/- mouse. J Virol 2009;83(16):8254-8258.

27. Sango K, Joseph A, Patel M, et al.: Highly active antiretroviral therapy potently suppresses HIV infection in humanized Rag2-/-gammac-/- mice. AIDS Res Hum Retroviruses 2010;26(7):735-746.

28. Kim YB, Lee MK, Han DP, and Cho MW: Development of a safe and rapid neutralization assay using murine leukemia virus pseudotyped with HIV type 1 envelope glycoprotein lacking the cytoplasmic domain. AIDS Res Hum Retroviruses 2001;17(18):1715-1724.

29. Conley AJ, Kessler JA, 2nd, Boots LJ, et al.: The consequence of passive administration of an anti-human immunodeficiency virus type 1 neutralizing monoclonal antibody before challenge of chimpanzees with a primary virus isolate. J Virol 1996;70(10):6751-6758.

30. Bailey J: An assessment of the role of chimpanzees in AIDS vaccine research. Altern Lab Anim 2008;36(4):381-428.

31. Boyer JD, Ugen KE, Wang B, et al.: Protection of chimpanzees from high-dose heterologous HIV-1 challenge by DNA vaccination. Nat Med 1997;3(5):526-532.

32. Fultz PN, Nara P, Barre-Sinoussi F, et al.: Vaccine protection of chimpanzees against challenge with HIV-1infected peripheral blood mononuclear cells. Science 1992; 256(5064):1687-1690.

33. Girard M, Kieny MP, Pinter A, et al.: Immunization of chimpanzees confers protection against challenge with human immunodeficiency virus. Proc Natl Acad Sci USA 1991;88(2):542-546.

34. Ourmanov I, Bilska M, Hirsch VM, and Montefiori DC: Recombinant modified vaccinia virus ankara expressing the surface gp120 of simian immunodeficiency virus (SIV) primes for a rapid neutralizing antibody response to SIV infection in macaques. J Virol 2000;74(6):2960-2965. 
35. Ourmanov I, Brown CR, Moss B, et al.: Comparative efficacy of recombinant modified vaccinia virus Ankara expressing simian immunodeficiency virus (SIV) Gag-Pol and/or Env in macaques challenged with pathogenic SIV. J Virol 2000;74(6):2740-2751.

36. Gardner MB and Luciw PA: Macaque models of human infectious disease. ILAR J 2008;49(2):220-255.

37. Shultz LD, Ishikawa F, and Greiner DL: Humanized mice in translational biomedical research. Nat Rev Immunol 2007;7(2):118-130.

38. Manz MG and Di Santo JP: Renaissance for mouse models of human hematopoiesis and immunobiology. Nat Immunol 2009;10(10):1039-1042.

39. Pearson T, Greiner DL, and Shultz LD: Humanized SCID mouse models for biomedical research. Curr Top Microbiol Immunol 2008;324:25-51.

40. Mosier DE, Gulizia RJ, Baird SM, and Wilson DB: Transfer of a functional human immune system to mice with severe combined immunodeficiency. Nature 1988;335(6187): 256-259.

41. Tary-Lehmann M and Saxon A: Human mature T cells that are anergic in vivo prevail in SCID mice reconstituted with human peripheral blood. J Exp Med 1992;175(2):503-516.

42. Amadori A, Veronesi A, Coppola V, et al.: The hu-PBL-SCID mouse in human lymphocyte function and lymphomagenesis studies: Achievements and caveats. Semin Immunol 1996; 8(4):249-254.

43. Brooks DG, Hamer DH, Arlen PA, et al.: Molecular characterization, reactivation, and depletion of latent HIV. Immunity 2003;19(3):413-423.
44. Brooks DG, Kitchen SG, Kitchen CM, et al.: Generation of HIV latency during thymopoiesis. Nat Med 2001;7(4): 459-464.

45. Choudhary SK, Archin NM, Cheema M, et al.: Latent HIV-1 infection of resting CD4(+) T cells in the humanized Rag2(-)/ (-) gammac(-)/(-) mouse. J Virol 2012;86(1):114-120.

46. Bleul CC, Wu L, Hoxie JA, et al.: The HIV coreceptors CXCR4 and CCR5 are differentially expressed and regulated on human T lymphocytes. Proc Natl Acad Sci USA 1997;94(5):1925-1930.

47. Picchio GR, Gulizia RJ, Wehrly K, et al.: The cell tropism of human immunodeficiency virus type 1 determines the kinetics of plasma viremia in SCID mice reconstituted with human peripheral blood leukocytes. J Virol 1998;72(3): 2002-2009.

48. Gulizia RJ, Collman RG, Levy JA, et al.: Deletion of nef slows but does not prevent CD4-positive T-cell depletion in human immunodeficiency virus type 1-infected humanPBL-SCID mice. J Virol 1997;71(5):4161-4164.

Address correspondence to:

Young Bong Kim Department of Bio-industrial Technologies College of Animal Bioscience and Technology

Konkuk University

Seoul 134-701

Korea

E-mail: kimera@konkuk.ac.kr 